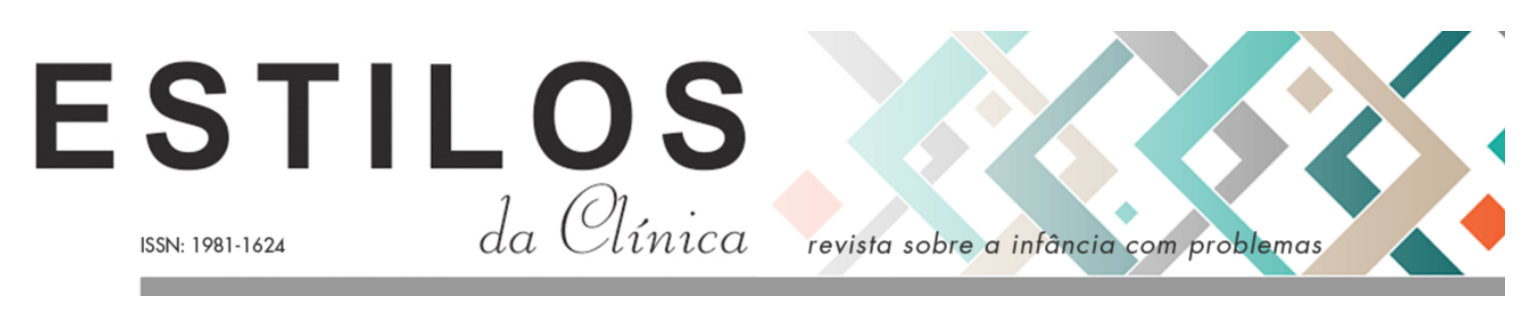

DOI: https://doi.org/10.11606/issn.1981-1624.v26i3 p476-493.

\title{
Dossiê
}

\section{Contribuições da psicanálise no Acompanhamento Terapêutico de crianças: uma revisão da Revista Estilos da Clínica}

\author{
Anaís Oliveira Caribé Cavalcante; Milena Silva Lisboa
}

Resumo. A presente revisão de literatura se propõe a analisar algumas contribuições da Psicanálise para a clínica do Acompanhamento Terapêutico (AT) com crianças, revisitando artigos da revista Estilos da Clínica - USP. Neste artigo, interroga-se acerca do acompanhante terapêutico (at), suas funções e a possibilidade de conexão com o desejo da criança em sofrimento psíquico. Foram analisados 13 artigos sobre Acompanhamento e Infância publicados na revista. A partir de uma leitura interpretativa, foram construídas três categorias: Acompanhamento Terapêutico (estrutura, formação e ética do dispositivo); Acompanhamento Terapêutico com crianças; e Acompanhamento Terapêutico com crianças autistas, psicóticas ou sem diagnóstico fechado. Assim, compreendese a psicanálise como um excelente recurso teórico para o norteamento do Acompanhamento Terapêutico, visto que sua aposta subjetiva pode ser um trampolim para o desenvolvimento infantil.

Palavras chave: acompanhamento terapêutico; psicanálise; criança; autismo; psicose.

\section{Contribuciones del psicoanálisis en el acompañamiento terapéutico de los niños: una revisión del periódico Estilos da Clínica}

Resumen. La presente revisión de la literatura propone analizar aportes del Psicoanálisis a la clínica de Acompañamiento Terapéutico (AT) con niños, revisitando artículos del periódico Estilos da Clínica (USP). Si investigó acerca del acompañante terapéutico (at), sus funciones y la posibilidad de conexión con el deseo del niño en la "angustia psicológica". Se analizaron trece artículos sobre Acompañamiento y Infancia. A partir de una lectura interpretativa se identificaron tres categorías: Acompañamiento Terapéutico (estructura, formación y ética del dispositivo); Acompañamiento terapéutico con niños y; Acompañamiento terapéutico con niños autistas, psicóticos o no diagnosticados. Así, el psicoanálisis se entiende como un excelente recurso teórico para orientar el Acompañamiento Terapéutico, ya que su apuesta subjetiva puede ser un trampolín para el desarrollo infantil.

\footnotetext{
* Psicóloga clínica e Acompanhante Terapêutica, membro da Clínica Laços, Salvador, BA, Brasil. E-mail: anais.nay@gmail.com

** Psicóloga clínica e Acompanhante Terapêutica. Professora Adjunta da Escola Bahiana de Medicina e Saúde Pública, Salvador, BA, Brasil. E-mail: milenalisboa@bahiana.edu.br
} 
Palabras clave: acompañamiento terapéutico; psicoanálisis, niño; autismo; psicosis.

\title{
Contributions of psychoanalysis in the therapeutic accompaniment of children: A review of the scientific journal Estilos da Clínica
}

\begin{abstract}
The present literature review aims to analyze some contributions of Psychoanalysis to the clinic of Therapeutic Accompaniment (TA) with children, revisiting articles from the scientific journal Estilos da Clínica USP. In this article, we ask about the therapeutic accompaniment (ta), its functions and the possibility of connection with the desire of the child in psychological distress. Thirteen articles published in the journal on Accompaniment and Childhood were analyzed. From an interpretative reading, three categories were built: Therapeutic Accompaniment (structure, formation and ethics of the device); Therapeutic Accompaniment with children; and Therapeutic Accompaniment with autistic, psychotic or undiagnosed children. Thus, psychoanalysis is understood as an excellent theoretical resource for guiding Therapeutic Accompaniment, since its subjective bet can be a springboard for child development.
\end{abstract}

Keywords: therapeutic accompaniment; psychoanalysis; child; autism; psychosis.

\section{Contributions de la psychanalyse dans le suivi thérapeutique de l'enfant : une revue de la journal scientifique Estilos da Clínica}

Résumé: Cette revue de littérature vise à analyser des contributions de la psychanalyse à la suivi thérapeutique (ST) des enfants, parmi des articles publies dans le jourmal scientifique Estilos da Clínica - USP. Dans cet article, des questions sont posées sur le compagnon thérapeutique (ct), leurs fonctions et la possibilité de liaison avec le désir de l'enfant en détresse psychologique. Treize articles à propos de la ST et l'Enfance publiés dans le journal ont été sélectionnés. A partir d'une lecture interprétative, trois catégories de suivi ont été établi: suivi thérapeutique (structure, formation et éthique du dispositif); suivi thérapeutique chez l'enfant; et suivi thérapeutique chez l'enfants autiste, psychotique ou sans diagnostic évident. Ainsi, la psychanalyse est comprise comme une excellente ressource théorique pour guider le suivi thérapeutique, puisque le pari subjectif que ce champ clinique donne au sujet peut être un tremplin pour le développement de l'enfant.

Mots clés : suivi thérapeutique; psychanalyse; enfant; autisme; psychose.

$E_{\text {ste texto se propõe a explorar as funções exercidas pelo acompanhante terapêutico (AT) }}{ }^{1}$ no seu processo de trabalho, a partir da perspectiva da Psicanálise, tendo como principal objetivo refletir sobre as dificuldades, desejos, processos de formação e supervisão.

Aproximando-se dos dispositivos desenvolvidos junto às crianças, o AT enfrenta o desafio de apostar na intervenção precoce a partir do momento de apresentação dos primeiros traços de autismo na primeira infância. Apesar do crescente número de casos reportados, ainda não se têm dados precisos sobre os retratos do autismo no Brasil. Nos Estados Unidos, o CDC (Center of Deseases Control and Prevention, 2020) - órgão ligado ao governo americano - afirma que, atualmente, existe um caso de autismo a cada 59 pessoas. Destarte, em vista dessa grande incidência reportada desde a infância, este artigo se propõe a analisar as contribuições da Psicanálise no campo de AT para esse possível modo de existência.

O objeto de estudo deste trabalho, no entanto, não se fixa na explicação patológica do autismo, mas sim na reflexão do percurso de construção do dispositivo clínico do

\footnotetext{
${ }^{1}$ Utilizando a diferenciação convencionada e encontrada em Duarte Barretto (1998, p. 17): “AT” (em maiúsculo) designará aqui Acompanhamento Terapêutico, e "at' refere-se ao acompanhante terapêutico
} 
Acompanhamento Terapêutico na perspectiva da Psicanálise, de modo a trazer uma compreensão de sujeito que faz frente às abordagens predominantemente cognitivocomportamentais encontradas na literatura.

No que se refere ao tratamento do Transtorno do Espectro do Autismo (TEA), o AT permite oferecer perspectivas próprias de como essa teoria enxerga a constituição do sujeito, confrontando a maneira biologicista de pensar o transtorno. Vale pontuar que a primeira infância é crucial ao desenvolvimento e à estimulação precoce de atividades sociocomunicativas que são justamente os pontos que conceituam essa condição de saúde. É propósito da psicanálise pensar o diagnóstico na infância como um estado e não como uma sentença definitiva (Jerusalinsky, 2016). Neste trabalho, engendra-se um breve debate acerca da perspectiva psicanalista sobre os diagnósticos não decididos nesse período de desenvolvimento humano.

Sendo assim, faz parte deste trabalho a reflexão sobre as contribuições da Psicanálise para o Acompanhamento Terapêutico de crianças. Como objetivos específicos, têm-se: analisar a Revista Estilos da Clínica a partir do descritor de Acompanhamento Terapêutico, considerandoa como uma referência nesse campo teórico; identificar as funções do AT a partir da Psicanálise; refletir sobre estratégias psicanalíticas que aportam conceitos e manejos ao cuidado do AT junto às crianças.

\section{Conceito}

O Acompanhamento Terapêutico é uma dispositivo terapêutico que se utiliza de técnicas próprias para o desenvolvimento de atividades cotidianas de pessoas com dificuldades em seu funcionamento social. Pode ser pensada como clínica de rua ou clínica em ato e sua mais importante função é a de (re)estabelecer o laço social com o Outro ${ }^{2}$. Para ocupar esse lugar, pode ser necessário utilizar-se de instrumentos funcionais em direção ao contato com uma abrangência do mundo e, às vezes, até mesmo estratégias de interdição e contenção psíquicas para a formação de bordas subjetivas, com o intuito de que se crie no sujeito uma noção de si e de seu próprio desejo em relação às suas condições no mundo. Segundo Jerusalinsky (2016, p. 39), o "problema é que, ao poupar alguém de qualquer desafio que possa comportar uma frustração, impede-se o encontro com qualquer falta capaz de engendrar a realização de um ato desejoso". Por isso, o trabalho do AT é minucioso, cauteloso, necessita de estudo e apropriação teórica. Para Mauer e Resnizky (1988, citados por Hermann, 2005, p. 62)

Ao estabelecer um contato cotidiano com o paciente, o acompanhante terapêutico poderá obter uma informação fidedigna sobre o comportamento do mesmo na rua, dos vínculos que mantém com os membros da família, do tipo de pessoas com que prefere se relacionar, das emoções que o dominam. Registrará também condutas chamativas da vida cotidiana em relação à alimentação, ao sono, à higiene pessoal. Tudo isso favorecerá em menor tempo uma compreensão global do paciente por

\footnotetext{
2 "um grande Outro que não é um semelhante, que J. Lacan escreveu com A maiúsculo, "um grande A", para distingui-lo do parceiro imaginário, o pequeno outro." Ou "Lugar onde a psicanálise situa, além do parceiro imaginário, aquilo que, anterior e exterior ao sujeito, não obstante o determina." (Chemama, 1995, p. 35).
} 
parte da equipe e servirá como indicador de diagnóstico e prognóstico de inestimável valor.

Dessa maneira, é na dificuldade do trabalho do AT que se concentra sua importância, beleza e potência.

\section{Histórico}

Data da década de 1950 o surgimento do Acompanhamento Terapêutico, a partir de demanda identificada de saída dos consultórios médicos e das alas psiquiátricas, como forma de reinserção do paciente no mundo social. Essa nova modalidade de cuidado nasceu alicerçada por conquistas do movimento antipsiquiátrico, antimanicomial e da psicoterapia nas instituições psiquiátricas. Aponta Nader (citado por Jerusalinsky, 2016, p. 31) que o AT "é um operador capaz de trazer novo rigor ao campo da reforma psiquiátrica, na medida que se manteve crítico e atento às modulações do sofrimento, tornando-se capaz de ler as novas formas de produção social da norma e da exclusão".

Segundo o site do Instituto A Casa (2019, s/p.), primeira clínica a escrever e trabalhar com Acompanhamento Terapêutico no Brasil, "Os principais expoentes desse movimento foram: Laing, Jones e Cooper, na Inglaterra; Basaglia, na Itália; Oury, na França; Tosquelles na Espanha e Szazs, nos EUA. Na América Latina, o AT surgiu no final da década de 1960, em Buenos Aires". Segundo Araújo (2005), ainda houve a influência de Félix Guattari, René Lourau e Georges Lapassade, autores do Movimento Institucionalista francês e da Esquizoanálise. No Brasil, o movimento começou na década de 1970, passando pelo sul do país e chegando a São Paulo, por meio da psicanalista argentina Beatriz Aguirre, do instituto supracitado.

O AT, inicialmente, era solicitado por psiquiatras e executado por profissionais das demais áreas de atuação na saúde mental. Segundo Rolnik (1997), o AT surgiu da necessidade de convivência das pessoas consideradas loucas com a sociedade, sendo uma prática itinerante e nômade, sem a caracterização de um atendimento domiciliar ou atendimento clínico, mas sim se posicionando como um processo de acompanhamento da vida cotidiana, com fundamentos terapêuticos. O dispositivo ultrapassa as paredes do consultório regular, sendo o seu espaço mais do que não-fixo, e sim móvel e fluido, com o lócus de atuação ocupando parques, casas, piscinas, praças, cinemas, praias, escolas, mercados, hospitais e demais espaços cotidianos.

Comumente, o trabalho é feito por profissionais ou estudantes de saúde, em especial das áreas de Psicologia, Fisioterapia e Enfermagem, constituindo-se, portanto, um dispositivo que não se restringe à Psicologia ou a qualquer outra formação. $O$ exercício do AT não é reconhecido como atividade profissional no Brasil, conforme consulta ao Cadastro Brasileiro de Ocupações $(\mathrm{CBO})^{3}$, diferentemente da Argentina, onde é uma profissão regulamentada.

\footnotetext{
${ }^{3}$ Consulta realizada em 23 de Novembro de 2019 na URL: http://www.mtecbo.gov.br/cbosite/pages/home.jsf, site do CBO de responsabilidade do Ministério do Trabalho.
} 
Além disso, o AT atende a pessoas diagnosticadas com diversas patologias, desde quadros de autismo, psicose, até depressão. Também pode atuar pontualmente em uma demanda específica, como em processo de hospitalização; nos casos de reabilitação ou cuidado temporário de idosos; junto a pessoas com retardo mental; com indivíduos acometidos por transtornos de alimentação; junto a adictos ou alcoolistas; no serviço com pacientes oncológicos ou terminais; bem como junto a pacientes com Alzheimer e/ou outras (psico)patologias (Pulice, 2005).

\section{Funções terapêuticas exercidas pelo acompanhante terapêutico}

A principal função do AT é reestabelecer a conexão do sujeito com o laço social, sendo uma ponte de intervenção para que isso aconteça. Segundo Jerusalinsky (2016, p. 15), "a pertença social que interessa é aquela que ocorre, não por uma simples adequação, mas por uma pertença desejante do sujeito ao social que se produz de modo sustentado no laço com os outros, pela qual se faz possível compartilhar". Desse modo, são inúmeras as intervenções possíveis nesse tipo de atividade, desde evitar internações, fazer e tomar empréstimos da subjetividade, oferecer barreiras simbólicas, disponibilizar aos sujeitos possibilidades novas de elaboração, mediar trocas entre o sujeito e o mundo e se relacionar efetivamente a partir de uma posição desejante e contributiva.

Tomando como base a Psicanálise apresentada por Barretto (1998), é possível tomar parte das seguintes funções do dispositivo terapêutico: holding (sustentação); continência; apresentação de objeto; manipulação corporal; descriminação entre a realidade psíquica e a realidade compartilhada; interdição; interlocução dos desejos e angústias; discriminação de campos semânticos; emergência da experiência estética (especular); alívio das ansiedades persecutórias; e modelo de identificação.

De acordo com o autor, essas funções seriam um compilado do que se pensa sobre a atuação em AT. Não necessariamente todos os recursos são utilizados de forma simultânea ou ostensiva, sempre variando de caso a caso. O holding, também representado em português pela palavra sustentação, é a ferramenta de maior presença ativa em qualquer que seja a situação, pois essa é a clássica função do "estar ali" para servir de aparato, de apoio e de alicerce ao paciente. Por meio de intervenções simples, o AT utiliza a sua posição de sustentação para propor novas alternativas de pensamento e ação, buscando sempre construir com o paciente as saídas para os próprios dilemas (Barretto, 1998). A presença encarnada do AT e o vínculo afetivo estabelecido permitem ao acompanhado suportar o laço social no convívio em sociedade, uma vez que o AT se empresta de modo a permitir que a circulação e a convivência sejam, aos poucos, conquistadas, a partir da segurança vincular oferecida.

No que se refere à função de continência, constitui-se como uma ação simbólica mais específica que permeia o estabelecimento de limites e ordens de uma maneira prioritariamente verbal, a fim de barrar a ação do paciente quando a mesma pode ser inadequada ou perigosa (Barretto, 1998).

A função de apresentação do objeto inspira-se na lição de objeto, discutida por Winnicott (1941, citado por Barretto, 1998) a partir do interesse do bebê, entre 5 e 13 meses, de ousar usar e separar-se do objeto. Cabe aqui uma breve explanação dessa situação, proposta em um experimento com bebês. Colocando uma espátula na mesa, Winnicott propõe esperar a reação 
do bebê. A primeira reação observada é a de hesitação, quando irá perceber, demonstrar interesse, fazer movimento em direção ao objeto, para em seguida olhar para o outro - um momento de inibição. O bebê olhará para a mãe e para Winnicott e vai pensar se esse movimento irá alterar o meio. Nesse momento, há de se esperar o movimento do bebê para não gerar a angústia desse conflito (Barretto, 1998). No segundo momento, o bebê pega a espátula - é o período de posse/uso - e a coloca na boca, passando a brincar com ela. Winnicott (1941, citado por Barretto, 1998) afirma tal movimento como expressão do viver criativo, enquanto capacidade do sujeito para usar o objeto e se apropriar dele; tomar um objeto da realidade compartilhada e transformá-lo em algo próprio, e assim brincar de várias formas. A salivação do bebê pode, nesses momentos, revelar a satisfação pulsional. Seria este um jogo de hesitação que não deve ser interrompido. O terceiro momento é a emergência da agressividade. A criança está pronta para ir embora, para se separar do objeto. A separação buscada e não temida. Nesse momento, pode-se terminar o encontro (Barretto, 1998).

É possível fazer uma analogia ao processo terapêutico, de acordo com Barreto (1998), a partir de tal experimento, pois também o trabalho terapêutico se organiza em um tempo determinado, com começo, meio e fim, assim como acontece no ritmo da vida. Num primeiro momento, a hesitação do paciente frente ao tratamento equivale à hesitação da criança diante do objeto. No segundo momento, adquire confiança no vínculo, na figura do analista em transferência e na figura real do analista. $O$ terceiro momento constitui-se pela capacidade analítica em autonomia do analista, quando o sujeito exerce a sua capacidade analítica fora da presença do analista.

No momento da hesitação, há angústia. No momento da confiança no vínculo, há comunicação do analista e do analisando. Existe compreensão do analista sobre o que busca, analisando-o naquele instante. O terceiro momento consiste no exercício da capacidade analítica do paciente, esperando-se que haja uma maior compreensão de seus processos inconscientes e dos efeitos de suas escolhas, até que se estabeleça o término da sessão. Não há nada mais que elaborar naquele encontro (Barretto, 1998).

A função de apresentação de objeto está relacionada à capacidade da mãe em se colocar exatamente onde ela fora alucinada. Capacidade de o ambiente sustentar o processo de ilusão e, gradualmente, fornecer experiências que apontam para a separação do eu e do não eu, modulando essa desilusão de tal forma que não coloca o eu bebê em dispersão, em angústia do aniquilado. O período é que vai dosar a experiência, proteger o bebê de um excesso de estímulo, mas também a capacidade de assimilação do bebê. A função de apresentação do objeto é exercida pelo meio ambiente. O bebê desenvolve a capacidade de realizá-lo. Os recursos a serem adquiridos são o tempo e o espaço, enquanto ato processual. Quando isso falha, a dificuldade e a capacidade em operar nessas dimensões aparece. O sujeito não sente que está no mundo (Barreto, 1998).

Existem alguns momentos em que o sujeito experimenta reações explosivas em resposta a alguma intervenção do acompanhante terapêutico, porque, naquele momento, vê-se ultrapassar o limite do que o sujeito é capaz de suportar, gerando um volume de angústia, que transborda em agressividade. É necessário se questionar sobre o que ocorreu e levar a cena para a supervisão. Quanto mais próximo o AT estiver transferencialmente do sujeito, maior será a compreensão desse processo.

A função da manipulação corporal, por sua vez, representa a conexão com necessidades básicas, como dormir, comer, tomar banho e tomar consciência do próprio corpo. Pode parecer 
óbvio, mas é exatamente porque é "tão obvio" e "fácil" que esses comportamentos precisam ser sinalizados pelo AT como importantes, no exercício de fazer a reconexão do sujeito com suas necessidades primordiais (Barretto, 1998).

Uma outra função elencada por Barretto (1998) é oferecer suporte para a discriminação da realidade subjetiva e a realidade compartilhada, permitindo que o sujeito separe o que é seu e o que é do outro no mundo, de modo que ele possa distinguir com maior nuance a sua participação e assim efetuar a elaboração psíquica de fatos.

Conquanto, por continência é possível compreender o delineamento de uma borda limitante, constituída de maneira subjetiva e falada, operada a partir da função da interdição, que ofereceria essa limitação feita in tempo $e$ in ato, estabelecendo limites reais para desejos e movimentos arriscados, perigosos ou lesivos a si e ao outro, muitas vezes, sendo necessário usar o próprio corpo para impedir situações intoleráveis.

É importante relembrar que AT é uma atividade multiprofissional, mesmo que, para a psicanálise, uma de suas funções seja fazer valer subjetivamente a marca deixada em terapia; por isso, apesar de não ser um requisito, o estudo desse campo clínico mostra-se fundamental, caso essa seja a linha de escolha do AT. Só assim será possível exercitar a função que Barreto (1998) chama de interlocução dos desejos e angústias.

$\mathrm{Na}$ função de discriminação de campos semânticos, o AT maneja os significantes, ampliando o repertório e permitindo o deslocamento de sentidos, uma vez que uma palavra pode adquirir diferentes significados a partir do contexto em que está inserida. Nessa função terapêutica, trata-se de "brincar" com as palavras em português, gerando um novo sentido e ressignificando as compreensões junto ao paciente. A palavra "partir", por exemplo, tem um campo semântico que permite identificar os sentidos de: sair, ir embora, "dar o fora", sumir, morrer, quebrar, espatifar. Do mesmo modo acontece com a palavra "estrela", que pode ter o significado de um astro no céu, uma pessoa famosa ou de um ser que vive no mar, podendo ainda ser nome próprio.

A chamada função especular, Barretto (1998) vai discorrer sobre o processo de identificação, citando Lacan e outros, mas priorizando a teorização winnicottiana. Para Winnicott (1941, citado por Barretto, 1998), o semblante da mãe vai expressar vários sentimentos endereçados ao filho, que começa a se reconhecer por meio da expressão facial materna. A mãe "empresta" seu corpo e o seu psiquismo em apoio ao bebê. Sendo assim, a função especular constitui-se em um movimento integrador da imagem do bebê e parte da sua experiência estética (unindo o corpo e a alma). É o encontro com o outro e, por conseguinte, com o seu próprio self, a partir da imagem e do sensório, reconhecendo que cada um privilegia um órgão sensorial. $\mathrm{O}$ acompanhante terapêutico é responsável por proporcionar essa diversidade de experiências.

Utilizada em casos específicos, mas sem diminuir a sua importância, tem-se a penúltima função: aliviar as ansiedades persecutórias, que busca ajudar a discriminar as ideias que perseguem o sujeito e trazer representações para elas, a fim de eliminar o sintoma ansioso persistente e, muitas vezes, transformado em delírio.

Por fim, o AT tem a função de ser um modelo de identificação do sujeito no mundo, alguém que vai "abrir portas" e expandir possibilidades, operando enquanto um retrato simbólico de diferentes perspectivas, a partir da expressão de novas significações para o que é real, permitindo transformações a partir de uma função simbólica. Barretto (1998) exemplifica que, certa vez, uma AT de sua equipe "simplesmente" recusou o jantar na casa da paciente, e isso 
funcionou como ferramenta simbólica para a mesma, que alegava não ter pensado na possibilidade de negar algo da rotina, mesmo que estivesse sem fome ou enjoada, agora, percebendo-se passível de fazê-lo.

\section{O Acompanhamento Terapêutico junto a crianças típicas}

Se a ideia de uma "clínica de rua" consegue fazer sentido com os pacientes que são diagnosticados já na adultez; com as crianças, o dispositivo do Acompanhamento Terapêutico é ainda mais significativo, porquanto elas estão no início do processo de desenvolvimento e de maturação biológica. Os laços que se criam, conectam - ou podem conectar - permanentemente a configuração sintomática que ali se constrói.

O direcionamento da cura para o trabalho do AT é diferenciado da concepção de "cura" vista nos manuais médicos, já que essa ferramenta não propõe a retirada do sintoma do paciente como forma de resultado de trabalho, mas sim uma aposta de que o sujeito pode encontrar novos locais ou maneiras de manifestar o seu inconsciente. Sendo assim, não existe patologia específica para o encaminhamento para um AT, basta que o sujeito tenha dificuldades na sua vida cotidiana e/ou relacional para demandar esse apoio.

Interseccionando as múltiplas possibilidades de recortes que se podem construir na atuação do AT, tanto em tipos de cuidado como em formatos, têm-se inúmeras possibilidades de atuação.

\section{Método}

Para atingir o objetivo deste artigo, a estratégia metodológica escolhida foi a revisão de literatura, pois a mesma sintetiza resultados obtidos no tema de maneira ordenada. Segundo Souza (2018, p. 4), a revisão de literatura "consiste na análise da literatura recente ou atual. Pode abranger uma ampla gama de assuntos em vários níveis de abrangência. Pode incluir os resultados da pesquisa". Assim sendo, no tocante à natureza da pesquisa, trata-se de uma revisão narrativa, de natureza qualitativa, que faz uma correlação literária com obras basais da Psicanálise sobre o tema.

O banco de dados escolhido para a análise integrativa tem como base as 52 edições da Revista Estilos da Clínica indexadas no PEPSIC. Como critérios de inclusão, foram selecionados artigos a partir do cruzamento de dois descritores, a saber: "Acompanhamento Terapêutico" e "autismo". As publicações selecionadas partiram do critério de disponibilidade integral e em versão on-line, sem recorte temporal, ao passo que os critérios de exclusão partiram da não abordagem temática ou psicanalítica ou que não estivessem disponibilizados em plataformas digitais. Após pesquisa com os descritores, foram encontrados 13 artigos que versam sobre o Acompanhamento Terapêutico junto a crianças autistas, a partir da perspectiva da psicanálise. Foi a partir desse composto literário que se materializou a análise que se segue, 
tomando outras obras para a composição do referencial teórico que pensem sobre autismo e psicose $\mathrm{e}^{4}$, a partir da psicanálise.

Após a leitura de todos os artigos e a identificação das temáticas mais recorrentes, foram construídas três categorias analíticas, a saber: "1. Acompanhamento Terapêutico enquanto dispositivo clínico (estrutura, formação e ética)", "2. Acompanhamento terapêutico com crianças típicas e atípicas" e "3. Acompanhamento Terapêutico com crianças autistas, psicóticas ou sem diagnóstico fechado”. Os resultados das análises e discussões realizadas seguem a seguir.

\begin{tabular}{|c|c|c|c|}
\hline Artigo & Autor & Ano & Categoria \\
\hline $\begin{array}{l}\text { Sabe-se sobre a criança? Acompanhamento } \\
\text { terapêutico e educação inclusiva }\end{array}$ & Spagnuolo, L. S. & 2017 & 2 \\
\hline Uma acompanhante terapêutica para duas & Gerab, C. K. & 2016 & 2 \\
\hline $\begin{array}{c}\text { Acompanhamento terapêutico escolar e } \\
\text { autismo: caminhos para a emergência do } \\
\text { sujeito. }\end{array}$ & $\begin{array}{l}\text { Nascimento, } \\
\text { V. G., Silva, A.S. } \\
\text { P., Dazzani, M. } \\
\text { V.M. }\end{array}$ & 2015 & 3 \\
\hline $\begin{array}{l}\text { Entre o pedagógico e o terapêutico: } \\
\text { Algumas questões sobre o acompanhamento } \\
\text { terapêutico dentro da escola }\end{array}$ & $\begin{array}{l}\text { Fraguas, V., } \\
\text { Berlinck, M. T. }\end{array}$ & 2001 & 3 \\
\hline $\begin{array}{c}\text { Considerações sobre o enquadre na clínica } \\
\text { do AT. }\end{array}$ & $\begin{array}{l}\text { Gerab, C. K. } \\
\text { Berlinck, M.T. }\end{array}$ & 2012 & 1 \\
\hline $\begin{array}{l}\text { Acompanhamento terapêutico, sua criação } \\
\text { em uma montagem institucional de } \\
\text { tratamento e as ofertas de laço social }\end{array}$ & $\begin{array}{l}\text { Hermann, M. } \\
\quad \text { C. }\end{array}$ & 2010 & 2 \\
\hline $\begin{array}{l}\text { A escrita e a constituição do sujeito: um } \\
\text { caso de autismo }\end{array}$ & Melão, M. S. & 2008 & 3 \\
\hline $\begin{array}{l}\text { O significante e o real na psicose: } \\
\text { ferramentas conceituais para o } \\
\text { acompanhamento terapêtutico }\end{array}$ & $\begin{array}{l}\text { Hermann, M. } \\
\quad \text { C. }\end{array}$ & 2005 & 3 \\
\hline $\begin{array}{l}\text { A mulher que não existe no laço social: um } \\
\text { caso de paranoia. }\end{array}$ & $\begin{array}{l}\text { Almeida, B. } \\
\text { H. M. }\end{array}$ & 2005 & 3 \\
\hline Do amigo qualificado à política da amizade & Araújo, F. & 2005 & 1 \\
\hline $\begin{array}{l}\text { Quantos paus se faz um acompanhamento } \\
\text { terapêutico?: contribuições da Psicanálise a } \\
\text { essa clínica em construção }\end{array}$ & $\begin{array}{l}\text { Guenra, A. } \\
\text { M. C., Milagres, } \\
\text { A. F. }\end{array}$ & 2005 & 1 \\
\hline $\begin{array}{l}\text { Acompanhamento terapêutico: vertigens da } \\
\text { clínica no concreto da cidade }\end{array}$ & $\begin{array}{r}\text { Palombini, } \\
\text { A. L., Cabral, K. } \\
\text { V., Belloc, M. M. }\end{array}$ & 2005 & 1 \\
\hline $\begin{array}{c}\text { Acompanhamento terapêutico: contexto } \\
\text { legal, coordenadas éticas e responsabilidade } \\
\text { profissional }\end{array}$ & $\begin{array}{l}\text { Pulice, G. } \\
\text { O., Manson, F., } \\
\text { Teperman, D. }\end{array}$ & 2005 & 1 \\
\hline
\end{tabular}

Quadro 1: Artigos coletados

${ }^{4}$ Por que psicose? Muitas vezes, no texto, os conceitos de Autismo e Psicose aparecerão associados. Isso se dá pela reflexão psicanalítica de que a psicose pode ser uma direção de desenvolvimento do autismo. 
Foram encontrados cinco artigos falando sobre Acompanhamento Terapêutico em geral, os quais pontuam acentuadamente o surgimento da clínica do Acompanhamento Terapêutico e da relação que o AT tem com a cidade e com o movimento. Para discutir os resultados encontrados, trabalha-se aqui contextualizando cada achado da análise. Há também certa recorrência na citação de teóricos, inclusive, articulações com autores, como Foucault, Deleuze e Lacan sobre a forma de organização civilizatória mundial e seu funcionamento neurótico. O mundo funciona de maneira simbólica e, segundo Lacan, no seminário Le Sinthome (2007), a estruturação psíquica pode ser representada a partir do que ele vai chamar de "nó borromeano", sendo a formatação simbólica a maneira que predomina na estruturação neurótica, enquanto a psicose e o autismo estruturam-se predominantemente no Real; e a perversão dentro do círculo do imaginário e do simbólico.

Em um primeiro texto, aqui analisado, de autoria de Gerab e Berlinck (2012), podem-se encontrar questionamentos sobre a flexibilidade do setting do AT como um elemento interessante de trabalho, visto que ele se torna um "articulador" de redes, fugindo da rigidez clínica conhecida pela Psicologia. É uma modalidade da clínica que inclui os gestos, o corpo, o olhar e o toque. Esse autor assente que o corpo é o setting de trabalho, e o terapeuta tem seu corpo como palco da transferência. Então, pouco importa a cena que se estabelece ao redor daquele atendimento, mas sim as posições tomadas e as conduções postas para abrigar aquela relação.

Ainda nesse texto, destaca-se também a importância da vulnerabilidade psíquica do AT que precisa estar em terapia, devido ao risco de sobreimplicação no trabalho de terapeuta e o estabelecimento de angústia devido à natureza do trabalho:

Durante os anos de sua prática clínica, no futuro, muitas vezes, você duvidará da eficácia de seu trabalho. Encontrará pacientes que não melhoram, agarrados a seus sintomas mais dolorosos como um náufrago a um salva-vidas; viverá momentos consternados em que as palavras que lhe ocorrerão parecerão alfinetes de brinquedo agitados em vão contra forças imensamente superiores. Nesses momentos (que, acredite, serão frequentes) será bom lembrar que você sabe mesmo (e não só pelos livros) que sua prática adianta. Sabe porque a prática que você propõe a seus pacientes já curou ao menos um: você (Calligares, 2004, p. 12).

A cidade, então, é palco de uma relação que independe dela, mas acontece nela, e constitui um enquadre do setting da terapia, "o que faz valer o caráter terapêutico do acompanhamento é o vínculo, e ele se faz com tato, espera, e sustentação do enigma" (Gerab, \& Berlinck 2012, p. 103).

Pode-se notar também nessa categoria a discussão sobre a mudança de nomenclatura que, inicialmente, chamava-se "amigo qualificado", agora "acompanhante terapêutico", transmutação acompanhada de mudanças de perspectiva do exercício do AT, mesmo que a intervenção seja moldada pelos aspectos subjetivos de ambos os sujeitos no par acompanhanteacompanhado. O que se discutia no termo inicial era o nome "amigo", não a qualificação do trabalho, visto que o laço gerado é técnico, terapêutico e fraterno, mas designá-lo enquanto "amizade" pode desqualificar o exercício ali feito.

Esse é um papel profissional, uma vez que a desinstitucionalização da loucura está diretamente relacionada à sua aceitação social. O louco não é entendido pela sociedade e sua 
circulação nas ruas ainda é tida como perigosa, por isso, é necessário que um profissional - não um amigo - exerça a função de conexão daquele com o mundo. O louco não é ouvido por si só, e caberia então ao AT ecoar essa voz no mundo. Essa mudança nominal traz consigo um amadurecimento mais do que necessário ao exercício da profissão.

Em Palombini (2005), pode-se encontrar referências à filosofia deleuzeana, que define a subjetivação como "dobras de fora", a partir do ponto em que a clínica é pensada. É uma espécie de mescla entre o impessoal que está no mundo e a pessoalidade inerente ao trabalho de AT. Segundo essa autora, uma ferramenta possível na experimentação do AT é o conceito de Corpo Sem Órgãos (CsO), construído por Deleuze e Guattari (1972), no livro "O anti-édipo", que surge após os protestos de maio de 1968, na França. Primeiramente, o que seria um corpo se não um espaço de movimentação de um desejo? Depois, os órgãos, parte da estrutura de um organismo vivo, desempenham função de sobrevivência e especificidade. Sendo assim, o CsO seria a constituição de um ser sem função, sem destino, e sem movimento. Um corpo de pura expressão de gozo e desejo, um constante devir. E é neste corpo que, muitas vezes, o AT tem de intervir.

O Acompanhamento Terapêutico permite outros processos de subjetivação e sustentação de modos de pensar e viver na cidade contemporânea que, como já dito, é neurótica e "cheia de órgãos". Lançando mão do trabalho, pode-se ressaltar a potência que esse tem ao fazer essa conexão, visto que questiona toda a historicidade do setting analítico tradicional freudiano e consegue inserir um mundo dentro da clínica, ou melhor, a clínica dentro do mundo real.

No que tange à convocação desse profissional, Jerusalinsky (2016, p. 40), a partir da imagem abaixo, vai afirmar que "Cada vez que se dá uma virada na vida temos um momento no qual se revisita o jogo de forças que existe entre o Eu Ideal e os Ideais do Eu, ou seja, entre a potência imaginária que cada um tem e os ideais simbólicos de cuja realização alguém poderá vir a se orgulhar". E é nesse contexto que o AT pode ser convocado a intervir.

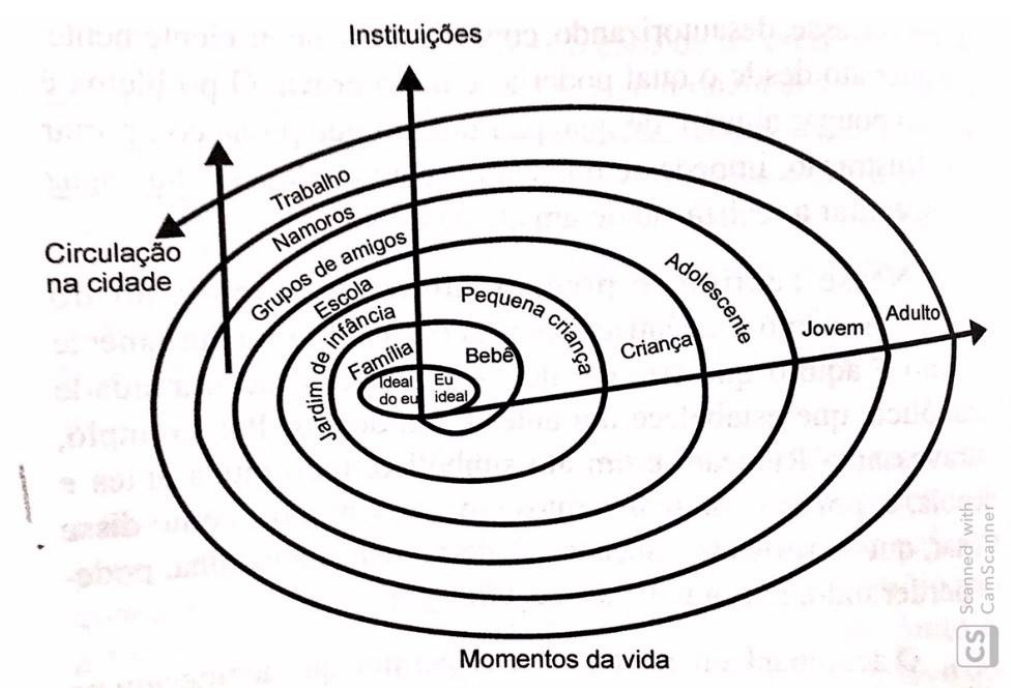

Figura 1: Momentos da Vida (Jerusalinsy, 2016). 


\section{Acompanhamento terapêutico com crianças típicas e atípicas}

A criação da categoria foi bastante elaborada, por constituir-se como uma categoria guardachuva que engloba seguintes; os três únicos artigos contidos nela falam sobre a o cuidado com uma criança com deficiência intelectual (DI) e outras crianças sem definição de diagnóstico. Entretanto, coube mantê-la, pois a clínica junto às pessoas com DI traz desafios importantes; falar do acompanhamento em geral pode trazer embasamento para pensar o acompanhamento específico com crianças autistas, psicóticas ou sem diagnóstico fechado.

Apesar do texto de Gerab (2016) contemplar a história de uma adolescente, trata-se de um rebaixamento intelectual por conta de uma síndrome cromossômica que lhe confere um aspecto infantil. Dessa maneira, considerou-se não o excluir na triagem. O texto relata que o "eterno bebê da família" adquire uma AT e que a mesma começa a servir duplamente dentro daquela casa por fazer uma escuta também dos familiares - principalmente da mãe - o que mobiliza a discussão sobre a tênue linha que separa a atividade da AT com a criança e com a família. Vale salientar que se deve tomar o cuidado de não fomentar a continuidade do paciente naquela posição familiar, na intervenção e no incentivo para a mudança da posição subjetiva. Esse suave obstáculo só consegue ser driblado, assim como no setting terapêutico tradicional, na escuta do inconsciente que se apresenta pela associação livre do paciente juntamente com a atenção flutuante do AT.

O outro texto que compõe essa categoria, escrito por Spagnuolo (2017), faz um traçado na história do Acompanhamento Terapêutico voltado à educação inclusiva, considerando que o que difere o ser humano dos animais instintivos e o torna pulsional é justamente por ser subvertido pela linguagem. E, nesse meio, o Outro preenche o vazio instintivo com a educação. A diferença de idade e a experiência são suficientes para a transmissão de conhecimento, ou seja, a educação é inerente ao ato de viver. Além disso, para conceber um sujeito, são necessárias marcas do Outro primordiais, instalando-se ali o desejo, a partir de sua inserção nos registros simbólicos aprendidos com a linguagem.

Quando Spagnuolo (2017), no que se refere ao processo de inclusão, critica a denominação de "criança incluída", assente que ela, por si só, pode se tornar uma inclusão perversa. Ainda que se tenham avanços de comportamentos cognitivos, podem-se configurar automatismos de imitação que não significam necessariamente a inclusão, já que esta é muito mais do que a adaptação do ser ao ambiente, trata-se de uma troca bilateral. Cita também que, hoje, na escola, é possível ver, com frequência, o Transtorno do Déficit de Atenção e Hiperatividade (TDAH), Transtorno Opositor Desafiador (TOD), o Transtorno do Espectro Autista (TEA), a Dislexia, o Distúrbio do Processamento Auditivo Central (DPAC), entre outros.

Cabe ressaltar que o que ocorre é que todos esses diagnósticos são feitos, comumente, por um neurologista ou psiquiatra que não vai à escola, e a Psicanálise enxerga o sinthoma do sujeito como uma forma de existência no mundo escolar. Vale diferenciar o sintoma clínico, caracterizado pela alteração de origem biológica que é tratável e direto, como uma coriza de gripe por exemplo, e o sinthoma, conceito Lacaniano que reflete o mal do qual o sujeito quer se livrar, de origem psíquica que se estabelece no corpo em forma de somatização. Em suma, "o sintoma é curável; o sinthoma não" (Jimenez, 2005, p. 14), ele somente se desloca ao longo da vida para locais mais suportáveis e socialmente aceitos, quando o sujeito percorre a direção da cura. Segundo Freud (1914), os sintomas têm um sentido e se relacionam com as experiências individuais de cada paciente. 
Então, de que maneira a saúde mental se manifesta como um sinthoma "fabricado" e que causa sofrimento? A psicanalista Kupfer (1989) afirma que:

\begin{abstract}
Uma pessoa que esteja sentindo frio poderá fazer uso de dois recursos: buscar uma vestimenta qualquer que a agasalhe, ou aproximar-se de uma fogueira. Nas duas situações, o alvo buscado - aquecer-se - será atingido. Mas a segunda pode trazer também um enorme prejuízo, caso a pessoa se aproxime demais do fogo e se deixe queimar: é nessa segunda categoria que se encaixa, analogamente, a loucura, que traz uma espécie de "destruição", mas fornece paralelamente uma forma de benefício secundário: o indivíduo se aquece, ainda que acabe por se queimar - consegue evitar o sofrimento psíquico, embora destrua radicalmente a conexão com a realidade. $O$ jogo está em determinar qual o mal menor, em que situação o desprazer será menos intenso. No caso do sistema neurótico, o indivíduo terá se aproximado da fogueira a ponta de se chamuscar nela, mas não estará destruído, e acabará por se aquecer, no final das contas (Kupfer, 1989, p. 53).
\end{abstract}

Assim, o transtorno muda de perspectiva, deixando de ser uma patologia que caracteriza a ausência de saúde e torna-se um recurso de sobrevivência do sujeito perante a sua história de vida. Compreende-se como um estado psíquico diferente da realidade neurótica na qual se está acostumado e uma nova forma de vida tão legítima quanto funcional. Para esse entendimento, é necessário quebrar os paradoxos patologizantes da sociedade para conseguir enxergar a saúde mental como uma alternativa na vida do sujeito. Um portador de transtorno mental pode viver a vida de maneira plena e estável.

O especialista que realiza o diagnóstico pode se sobrepor à escola ou dialogar com ela; é uma escolha profissional. Diante da "avalanche dos saberes médicos", o espaço escolar se torna impotente, e os professores sentem-se incapazes de exercer a educação, sendo que é neles que a real educação se encontra. O AT tem de mediar essa relação, mas, comumente, não é ele que formalmente ensina os conteúdos pedagógicos. "A desalienação por si só é terapêutica" (Spagnuolo, 2017, p. 8) e acaba sendo uma função do AT que porta um "discurso" sobre a criança. Spagnuolo afirma que o profissional só pode construir um saber caso se ponha ao lado da criança, e não se alicerce sore ela. Então, o trabalho do AT é construir junto com a criança, a partir do seu discurso e das pistas inconscientes fornecidas, um novo saber sobre ela e uma imagem diferente para os seus pares.

O trabalho do AT com crianças trata, diferentemente da conduta com adultos, da criação de condições para a emergência de uma estruturação da personalidade; no ambiente escolar, fazse necessário o vínculo construído entre o AT e a criança, pois existe uma diferenciação do que é pedagógico e o que é terapêutico. Na perspectiva de Kupfer (1997, p. 56), toda educação é terapêutica, e toda terapia é educativa - em algum momento do repertório escolar, esses dois saberes se entrelaçam.

\title{
Acompanhamento Terapêutico com crianças autistas, psicóticas ou sem diagnóstico fechado
}

Segundo Nascimento (2015), o acompanhante que assume a presença ativa vai cumprir exatamente esta função: ser o espelho da criança; realizando a interpretação das diversas formas de comunicação entre a criança, os colegas, a escola em si e a família. A primeira inclusão do bebê é em sua filiação, sua entrada na linguagem se inicia muito antes de começar a falar (Melão, 2008). De modo análogo, o AT garante a suposição do sujeito, pois reitera seu discurso 
social. Há investimento libidinal na existência daquela criança e no sentido das suas manifestações, oferecendo até mesmo a partir de uma pequena ecolalia a possibilidade de adquirir um sentido subjetivo.

Uma outra função fundamental do AT é a manutenção do laço social, questionando a invisibilidade da criança e tornando-a protagonista da sua própria história. Cabe também ao acompanhante terapêutico desconstruir os estereótipos relacionados à patologia, possibilitando aos professores e aos colegas perceberem as qualidades e capacidades da criança, diminuindo a dificuldade da interação social, mediando a linguagem e orientando as brincadeiras.

Ainda para Nascimento (2005), os sintomas encontrados, como estereotipias e rituais, são formas de existência do sujeito, pois produzem uma significação desconhecida. Percebe-se ainda como característica a ausência de sua percepção enquanto sujeito desejante e uma falha na constituição imaginária de si. A direção da cura para a Psicanálise, diferentemente da Psicopatologia médica, não tem o intuito de retirar sintomas, mas sim criar uma suplência sintomática que permita ao sujeito o desenvolvimento em sociedade a partir de sua condição existencial. O AT constrói, com cada indivíduo, seu próprio saber a partir das marcas inconscientes deixadas no cotidiano do relacionamento. Considera-se então a pluralidade de autismos e, por isso, a crítica aos métodos diagnósticos do DSM-V.

O transtorno do espectro autista é um novo transtorno do DSM-5 que engloba o transtorno autista (autismo), o transtorno de Asperger, o transtorno desintegrativo da infância, o transtorno de Rett e o transtorno global do desenvolvimento sem outra especificação do DSM-IV. Ele é caracterizado por déficits em dois domínios centrais: 1) déficits na comunicação social e interação social e 2) padrões repetitivos e restritos de comportamento, interesses e atividades (DSM V, 2013, p. 809).

Entretanto, desde uma mudança ocorrida do DSM-III para o IV (1992), houve supressão da categoria "psicoses infantis", o que contribui para a explosão diagnóstica do autismo, visto que dentro do TEA (DSM-V) encaixam-se várias categorias diagnósticas. Esse ponto também vai de encontro ao pensamento da Psicanálise, que considera a existência de uma possível psicose não decidida na infância.

O que a psicanálise pensa sobre o tema? Os enlaces psicanalíticos sobre o acompanhamento terapêutico na infância apontam que nos primeiros momentos de vida de um bebê, estabelecese um estado fusional (simbiótico) com a sua mãe (cuidador). Fala-se então, de um processo de alienação necessário para a constituição do sujeito. A mãe é a porta voz do grande Outro e, a partir do desejo da mesma, o bebê se coloca no mundo, constituindo-se, assim, um estado de plenitude para ele. O processo de constituição desse sujeito requer uma separação do estado fusional para que ele possa emergir como sujeito do próprio desejo. A separação dar-se-ia pela entrada de um terceiro no discurso materno, capaz de capturar o desejo dessa mãe, instaurando um estado de falta. Essa operação simbólica é denominada de função paterna (Nome-do-Pai), operação fundante que pode claudicar para alguns sujeitos. Dito isso, pode-se pensar a função do AT como esse lugar terceiro, que media a relação entre o sujeito e o grande Outro.

Ao passo que o AT exerce essa função de corte simbólico e estabelecimento de bordas, ele também faz, simultaneamente, a criação do vínculo de alienação, suporte importante para a sustentação do setting terapêutico. Segundo Barretto (1998, p. 12), o AT intenta propiciar ao sujeito "experiências que possam suprir determinada(s) fenda(s) no self".

$\mathrm{O}$ encontro da práxis do AT com os casos de autismo e psicose forma um enlace (quase) perfeito de trabalho, visto que as demandas específicas dos mesmos, relacionadas diretamente 
com o convívio social, são tomadas por aquele com tamanho encaixe, que o mesmo se faz ponte e empresta a sua subjetividade para a construção das amarrações simbólicas e subjetivas alheias. É um pouco do que fala Barretto (1998) na função especular, em que o sujeito se constitui a partir de um espelhamento do laço com o outro. Nesse momento, é importante verificar a preciosidade do trabalho do AT com as crianças, pois elas estão em efervescente estado de crescimento e maturação biológica e de constituição psíquica, fase mais que propícia à estimulação a tempo.

Afirma Jerusalinsky (2016) que a infância se define por quatro etapas decisivas: as três acima citadas e o desenvolvimento. $\mathrm{O}$ crescimento diz respeito à questão orgânica, ganho de peso, altura e massa corporal, fácil de ser medido e visualizado. A maturação seria um aspecto orgânico mais complexo, pois fala do processo anatomofisiológico que comporta o avanço das funções dos órgãos; ela tem tempos definidos e processos temporais esperados. Esse aspecto cria margem para se pensar em uma "janela neurológica", ou seja, um tempo de abertura a estímulos e incentivos. Após o fechamento dessas janelas, não é impossível a inscrição subjetiva na criança, mas torna-se mais difícil. Ainda citando Jerusalinsky (2016, p. 17), “o nosso princípio ético é intervir com quem chega para tratamento em uma situação de sofrimento, na idade em que for e com o corpo que tem".

O início da vida ( 0 a 3 anos) conta com a maior plasticidade neural e maior abertura para inscrições significantes. A constituição psíquica é a operação de subjetivação do bebê, na direção de tornar-se sujeito do seu próprio desejo. Segundo Elia (2004, p. 36), “[...] o sujeito se constitui, não 'nasce' e não se desenvolve", ele é constituído a partir dos laços sociais estabelecidos.

Para o surgimento do sujeito psíquico, faz-se necessário o encontro entre o alicerce biológico e uma estrutura familiar, transmissora do sistema simbólico (Bernardino, 2004, p. 28). Os processos de maturação, desenvolvimento e crescimento do bebê ficam pendentes, à espera de que a estruturação psíquica se arme. Para Medeiros e Mariotto (2006, p. 50), “[...] a subjetividade vai depender da instalação deste corpo num sistema de lugares que exigirá dele o exercício de uma função na sua relação com os outros lugares que compõem este sistema e como eles passarão a funcionar". O desenvolvimento, por sua vez, segundo Papalia at al. (2013, p. 661) trata-se de "[...] processos de transformação e estabilidade ao longo de todo ciclo de vida humana". Nesse sentido, Jerusalinsky (2016) lembra que é preciso considerar que a dimensão da infância está acima de qualquer patologia e, portanto, o investimento do profissional deve levar essa fase em consideração, sobrepondo-se ao processo patológico.

Mesmo que a carga genética definisse a psiqué humana, existe uma interação para com o mundo que interfere diretamente nessa construção, é o que se chama de epigenética, ou seja, a interação social associada a uma carga biológica já adquirida (Jerusalinsky, 2016).

Ao longo da vida, passa-se por uma "poda neural", pois o cérebro, com o crescimento e a maturação, perde em plasticidade neuronal, mas ganha em especificidade e funcionalidade. Freud afirma ao longo dos "Três Ensaios sobre a Teoria da Sexualidade" (1905) que a infância se caracteriza pelo polimorfismo das vicissitudes pulsionais. Sendo assim, alguns psicanalistas, como Jerusalinsky (2016), compartilham da ideia de que a estrutura psíquica não está definida na infância.

Considerando que, na adolescência, flagra-se mais uma transição que uma transitoriedade e, na infância, mais de uma transitoriedade do que de uma instalação; os diagnósticos na infância precisam ter a cautela de não se firmarem como definitivos, incuráveis ou crônicos. Ou seja, a 
menos que se tenha uma prova irrefutável em uma demonstração clínica suficientemente extensa do caráter inamovível, intransportável ou irremissivelmente deteriorante e degenerativo de determinada ficção, deve-se ter presciência acerca de determinações (Jerusalinsky, 2016, p. 41).

Isso significa que o trabalho do AT constitui-se ainda mais fundamental quando executado de maneira precoce, se considerado o devir da definição de estrutura psíquica. Além disso, muitas crianças diagnosticadas precocemente sofrem com uma "cola diagnóstica" e com o deslocamento subjetivo na interlocução família, escola e acompanhante terapêutico. Pensa-se, então, que a criança está "encaixada" naquela diagnose daquele momento, não que ela é o seu diagnóstico. Parece óbvio, contudo, na perspectiva da psicanálise, a importância do papel do AT na desconstrução dessa crença exatamente pela identificação da diferença.

Pode-se inferir que, somente ao final da adolescência, a estrutura estaria orgânica e psiquicamente definida, o que não significa o abandono do trabalho do AT, mas sim uma luminosidade no seu papel antes dessa definição psíquica. A direção desse trabalho é pela aposta de inscrições subjetivas de novas oportunidades, novos pensamentos, desenvolvimentos e de (re)inscrições em referência ao Outro, de modo a sustentar a imersão do sujeito como sujeito singular do seu próprio desejo.

\section{Considerações finais}

A Psicanálise pode contribuir para o Acompanhamento Terapêutico de crianças na medida em que assume o lugar de dar sustentação ao cotidiano do sujeito, seja ele quem for. A afirmação de indefinição do diagnóstico na infância pode representar uma potência para a restituição do laço social, uma aposta em potencial e uma forma de investimento no psiquismo do sujeito a fim de transformar o seu diagnóstico, mesmo que esse não seja o objetivo do trabalho, para melhorar a relação do sujeito com o Outro.

Assim, o papel do Acompanhamento Terapêutico não se restringe a eliminar uma defesa constituinte, nem seu sofrimento ou falta, mas de encontrar caminhos simbólicos junto com o paciente para que esse se encontre reconhecido e possa escolher um estilo para viver.

A intervenção a tempo, por sua vez, é uma das grandes ferramentas proporcionadas pelos acompanhantes terapêuticos, que têm, naquele momento específico, a possibilidade de contribuir para a estruturação psíquica do sujeito.

Dessa maneira, conclui-se que o Acompanhamento Terapêutico é duplamente a clínica do momento: por se situar na possibilidade da intervenção no tempo necessário; e por estar em emergência no mundo atual. Sendo assim, não importa se o diagnóstico médico aponta para um quadro de TEA, psicose ou outra condição; o AT vai buscar o favorecimento ou a reconciliação do encontro com o Outro.

\section{Referências}

Araújo, F. (2005). Do amigo qualificado à política da amizade. Estilos da Clín., 10(19), 84105. Recuperado de http://pepsic.bvsalud.org/scielo.php?script=sci_arttext\&pid=S1415$\underline{71282005000200005}$ 
Barretto, K. (1998). Ética e técnica no acompanhamento terapêutico. São Paulo: Unimarco.

Bernardino, L. M. F. (2004). As psicoses não decididas da infância: Um estudo psicanalítico. [Versão digital em Adobe Reader]. Recuperado de http://www.niip.com.br/wpcontent/uploads/2013/05/As-psicoses-n\%C3\%A3o-decididas-da-inf\%C3\%A2nciaLeda.pdf.

Calligaris, C. (2004). Cartas a um jovem terapeuta. Rio de Janeiro: Elsevier. Chemama. (1995). Dicionário de Psicanálise Larousse. Porto Alegre: Artes Médicas Sul. Deleuze, G., \& Guattari, F. (1972). O Anti-Édipo: capitalismo e esquizofrenia. São Paulo, SP: Editora 34.

Elia, L. (2010). O Conceito de sujeito. (3a.ed.). Rio de Janeiro, RJ: Zahar.

Fraguas, V., \& Berlinck, M. T. (2001) Entre o pedagógico e o terapêutico Algumas questões sobre o acompanhamento terapêutico dentro da escola. Estilos Clín., 6(11), 7-16. doi: https://doi.org/10.11606/issn.1981-1624.v6i11p7-16

Freud, S., \& Salomão, J. (1973). Três ensaios sobre a teoria da sexualidade. Rio de Janeiro, RJ: Imago.

Gerab, C. K. (2016). Uma acompanhante terapêutica para duas. Estilos Clín., 21(1), 189-199. doi: https://doi.org/10.11606/issn.1981-1624.v21i1p189-199

Gerab, C. K., \& Berlinck, M. T. (2012). Considerações sobre o enquadre na clínica do AT. Estilos Clín., 17(1), 88-105. doi: https://doi.org/10.11606/issn.1981-1624.v17i1p88-105

Hermann, M. C. (2005). O significante e o real na psicose: ferramentas conceituais para o acompanhamento terapêutico. Estilos Clín., 10(19), 132-153. Recuperado de http://pepsic.bvsalud.org/scielo.php?script=sci arttext\&pid=S1415-71282005000200008

Hermann, M. C. (2010). Acompanhamento terapêutico, sua criação em uma montagem institucional de tratamento e as ofertas de laço social. Estilos Clín., 15(1), 40-59. doi:

https://doi.org/10.11606/issn.1981-1624.v15i1p40-59

Jerusalinsky, A. (2016). Travessias e Travessuras no acompanhamento terapêutico (1st ed.). Salvador: Agalma. Jerusalinsky, A. (2019). Dossiê Autismo (1st ed.). São Paulo: Langage.

Jimenez, S. (2005). Sinthoma e fantasia fundamental, Latusa Digital, Rio de Janeiro - EBP-RJ, (12).

Kupfer, M. C. (1989). Freud e a educação. O mestre do impossível. São Paulo, Scipione.

Kupfer, M. C. (1997). Educação terapêutica: o que a psicanálise pode pedir à educação. Estilos da Clínica, 2(2), 53-61. doi: https://doi.org/10.11606/issn.1981-1624.v2i2p53-61

Lacan, J. (2007). O seminário. Livro 23: o sinthoma. (1975-1976). Rio de Janeiro: Jorge Zahar. ISBN 978-8571109872

Medeiros, M. S.; Mariotto, R. M. M. (2006). O tempo da constituição do sujeito In L. M. F. Bernardino (Org.), O que a psicanálise pode ensinar sobre a criança, sujeito em constituição, 43- 55. São Paulo: Escuta.

Melão, M. S. (2008). A escrita e a constituição do sujeito: um caso de autismo. Estilos Clín., 13(25), 94-117. doi: https://doi.org/10.11606/issn.1981-1624.v13i25p94-117

Nascimento, V. G., Silva, A. S. P., \& Dazzani, M. V. M. (2015). Acompanhamento terapêutico escolar e autismo: caminhos para a emergência do sujeito. Estilos Clín.,20(3), 520-534. São Paulo. doi: https://doi.org/10.11606/issn.1981-1624.v20i3p520-534 
Palombini, A. L., Cabral, K. V., \& Belloc, M. M. (2005). Acompanhamento terapêutico: vertigens da clínica no concreto da cidade. Estilos Clín., 10(19), 32-59. Recuperado de http://pepsic.bvsalud.org/scielo.php?script=sci arttext\&pid $=\mathrm{S} 1415-71282005000200003$

Papalia, D., Olds, S., Feldman, R., Bueno, D., \& Frizzo, G. (2013). Desenvolvimento humano. Porto Alegre, RS: Artmed.

Pulice, G. O., Manson, F., \& Teperman, D. (2005). Acompanhamento terapêutico: contexto legal, coordenadas éticas e responsabilidade profissional. Estilos Clín., 10(19), 12-31. doi: https://doi.org/10.11606/issn.1981-1624.v10i19p12-31

Rolnik, S. (1997). Equipe de At Do Hospital-Dia “A Casa”. Crise e cidade: acompanhamento terapêutico. São Paulo, SP: EDUC.

Society, A., (2020). Autism Society Statement: CDC Releases Autism Prevalence Report. [online] Autism Society. Recuperado de https://www.autism-society.org/releases/cdcreleases-new-prevalence-rates-of-people-with-autism-spectrumdisorder/\#: : :text=CDC $\% 20$ Report $\% 20$ States $\% 20$ That $\% 20$ Prevalence, diagnosed $\% 20$ with $\% 20$ autism $\% 20$ spectrum $\% 20$ disorder

Sousa, L. M. M. de, Firmino, C. F., Marques-Vieira, C. M. A., Severino, S. S. P., \& Pestana, H. C. F. C. (2018). Revisões da literatura científica: tipos, métodos e aplicações em enfermagem. Revista Portuguesa de Enfermagem de Reabilitação, 1(1), 45-55. doi: https://doi.org/10.33194/rper.2018.v1.n1.07.4391

Spagnuolo, L. S. (2017). Sabe-se sobre a criança? Acompanhamento terapêutico e educação inclusiva. Estilos Clín., 22(2), 283-298. doi: https://doi.org/10.11606/issn.19811624.v22i2p283-298

Revisão gramatical: Lisandra Amparo Ribeiro Pimentel

E-mail: lispiment@hotmail.com

Recebido em agosto de 2020 - Aceito em agosto de 2021. 